\title{
KIRGIZ AILE VE SOSYAL - KÜLTÜREL HAYATINDA KADIN
}

\section{Ilknur BAYRAK IȘCANO $\breve{G} L U^{*}$}

\begin{abstract}
Özet
Kültür; bir toplumun geçmişi, bugünü ve geleceğidir; o topluma ait yaşanmışlıklar birikimidir. Bu birikimin nesiller arası devamlılığında toplumun bir parçası olan kadının önemli olduğu inkâr edilemez bir gerçektir. Kadın evinde mutfağındayken yaptığı yemekle, düğünde geline yaktığı kına ile torununa söylediği ninni ile farkında olmadan da olsa yaşadığı kültürün devamlılığını sağlamaktadır. Bu açıdan bakıldığında yaşam şekli ve içinde bulunulan kültür kadına hem aile içerisinde hem de toplum yaşantısında çeşitli roller yüklemiştir. Kadın; aile hayatı içerisinde anne, gelin, evlat, eș iken toplumsal hayat içerisinde de giyimiyle, medeni haliyle çeşitli tavır ve duruşa sahip olmuştur. Pek çok kültürde kadın; mutfak, ev ve çocuk bakımından sorumlu kişi olarak görülmüş ve bu anlayış çerçevesinde kadının dünyasının sınırları çizilmiştir. Dünya tarihinde kadına yönelik yapılan çeşitli toplumsal hareketlerle kadın evin dışına çıkarılmaya çalışılmış, kadınla ilgili algı ve düşünüş değiştirilmeye, kadının toplumsal hayatta etkin bir şekilde yer almasına çalışılmıştır. Türk kültüründe aile ve toplum hayatı içerisinde kadına her zaman değer verilmiştir. Türk kültür tarihine bakıldığında kadının yönetimde söz sahibi olduğu, kadının önemsendiği anlaşılmaktadır. Kırgız toplumsal ve kültürel hayatında da Kırgız kadınlarının çeşitli rolleri vardır. Kırgız kadınlarının da bir anne olarak çocuklarına, eş olarak hayat arkadaşına, aile büyügü olarak diğer aile fertlerine karşı çeşitli görevlere sahip olduklarını söylemek mümkündür. Bu çalışma ile Kırgız'ın düşünüşünde Kırgız kadınına yönelik algı ve tutumları görmek, Kırgız kadının sosyal ve kültürel hayattaki durumunu; eş, anne, evlat, aile büyüğ̈̈ olarak çeşitli rollere sahip Kırgız kadınını tanımak mümkün olacaktır.
\end{abstract}

Anahtar Sözcükler: Kültür, Kadın, Kırgız, Sosyal, Kültürel, Hayat.

\section{WOMEN IN KYRGYZ FAMILY AND SOCIAL - CULTURAL LIFE}

\begin{abstract}
Culture is a society's past, present and future. It is the accumulation of the society's experiences. It is an undeniable fact that as part of society, women are important for the continuity of this accumulation from generation to generations. Women ensure the continuity of their culture with the meals they cook, with the henna they apply to the hands of a bride and with the lullabies they sing for their grandchildren, without realizing it. From this perspective, lifestyle and culture have caused women to take on various roles in both family and social life. Women are mothers, brides, daughters and wives in the family life, and they have various attitudes and stances with their style of dressing and marital status in social life. In many cultures, women are considered responsible for cooking, domestic labor and childcare, and within the framework of this understanding, the boundaries of women's world are drawn. Various social movements for women in world history have attempted to break these boundaries, change perceptions and thoughts about women and enable them to actively participate in social life. In Turkish culture, women are valued in the family and in society. Turkish cultural history shows that women have had a say in the government and are considered important. Kyrgyz women have several roles in Kyrgyz social and cultural life. They have duties to their children as mothers, to their husbands as spouses and to other family members as senior family members. This study will describe perceptions of and attitudes towards Kyrgyz
\end{abstract}

\footnotetext{
* Dr., Türk Dili Okutmanı, Gazi Üniversitesi TÖMER Müdürlüğü, el-mek: ilkcan04@ hotmail.com

(D) ORCID ID: https://orcid.org/0000-0002-2849-4992
} 
women, their status in social and cultural life and their roles as spouses, mothers, daughters and senior family members.

Key Words: Culture, Women, Kyrgyz, Society, Life.

\section{Giriş}

Kadın, Türk kültüründe her zaman değerli görülmüştür. Türk mitolojisinde, destanlarında kadına verilen değeri görmek mümkündür. Kadın; iffet sahibi, akıllı, danışılan kişi olarak anlatılarda görülür. Özellikle Altay mitolojisinde Tanrı Ülgen'in dünyayı Ak İne'nin kendisine söylemesiyle oluşturduğu şeklinde geçen anlatıda Tanrı'ya ilham verenin kadın olması dikkat çekicidir( İnan,1998:274). İslamiyet öncesi ve sonrası Türk destanlarında da kadının önemli olduğu görülmektedir: Oğuz Kağan Destanında kadın; yaşayışın devamında at ve oktan sonra birleştirici önemli bir unsur olarak görülürken Dede Korkut Hikâyelerinde ise eş olarak kadınların akıl alınan, danışılan kişiler olmaları dikkat çekicidir ( Şen, 2003: 124). Türk kültüründe, devlet yönetiminde, aile yaşantısında önemli görülen kadınlar, çeşitli kültürlerde ise maalesef değersiz görülmüşlerdir. Özellikle Orta Çağ Avrupası'nda kadın değersizdir. Hatta 15.ve 17. yüzyıl Avrupası'nda pek çok kadın cadı olarak isimlendirilerek öldürülmüşlerdir ( Coşar, 2013: 57). Dünya tarihinde kadınların erkekler karşısındaki sindirilmiş hallerine karş1lık toplu kadın hareketleri yaşansa da kadının toplumdaki yeri pek de değişmemiştir.

Kadın deyince akla ev, mutfak ve çocuk bakımı gelmektedir. Kadını evin simgesi haline getiren bu anlayış dünya üzerindeki pek çok kültürde geçerlidir. Farklı kültürlerdeki ortak görüşe göre kadın ev işlerinden ve çocuk bakımından sorumludur. Kadının toplum hayatı içerisinde dar bir alana sıkıştırılmış olması durumu yeni değil hatta insanlığın ilk yıllarına, ilkel dönemlere kadar uzanan bir süreçtir. Avcılık ve toplayıcılıkla geçinen ilkel toplumlarda özel mülkiyet anlayışı oluşmaya başlayınca erkek ve erkeğin yaptığı işler önemli hale gelmiş, kadın ve kadınla ilgili işler önemsiz gibi görülmüştür. Aslında önceleri kadın topluluğu yönetendir. Toplumla ilgili pek çok düşünce ve hareket kadına bağlıdır. Topluluktaki beslenme, barınma, örtünme yine kadının sorumluluğundadır ( Coşar,2013: 35). Anaerkil olarak adlandırılan bu dönemden ataerkil döneme geçişte, pek çok araştırmacıya göre kadının evi ile sınırlı hale gelmesinde hem yerleşik hayata geçmenin etkisi hem de dinin etkisi bulunmaktadır. Yerleşik hayatla birlikte, Avrupa'daki sanayi devrimi ile erkekler bahçelerinden dışarı çıkmışlar ve kadın içinde yaşadığı evinde erkeği bekleyen kişi rolü kazanmıştır. Kadının yaşam alanının sınırlandırılmasıyla birlikte kadın deyince akla ev, mutfak ve çocuk gelir olmuştur. Dünya tarihindeki Fransız Devrimi, Sanayi Devrimi gibi gelişmeler kadının toplumsal hayattaki yerini etkilemiştir. Kadın, dünyadaki bu gelişmelerle dış dünyada yani sosyal ve toplumsal hayatta yer bulmaya başlamıştır. Türk Dünyasını yakından ilgilendiren Sovyetler Birliği Dönemi’nde de kadına yönelik çalışmalar yapılmıştır. Bu dönemde Çarlık Rusya'daki kadını değersiz ve bir hiç gören anlayış yıkılmaya ve kadının her alanda ( eğitim, sanat, siyaset, ekonomi...) özgür olması sağlanmaya çalışılmıştır. Bu dönemde çalışan kadın sayısı artırılmış, kadın ve erkekler arasındaki çalışma ve ücret karşılıkları eşitlenmiştir ( Hasdemir, 1991: 89). Ayrıca Sovyetler Birliği öncesindeki Çarlık döneminde kadını bir madde gibi gören anlayış yıkılmaya çalışılmış ve çok eşlilik, kaçırarak evlenme, başlık parası gibi durumların yasaklanması yoluna gidilmiştir( Coşar, 2013: 318). Bu gelişmeler 1şığında 18. ve 20. yüzyıllar arasında Türk Dünyası'nda kadın, ataerkil bir aile yapısı içerisinde görülür. Kadının aile ve toplumsal hayattaki yeri erkeğe bağlıdır. Özellikle Türk dünyasında kadınlar yaşadıkları yerlere ( şehir ya da kırsal) göre farklı rollere ve yaşam şekillerine sahip olmuşlardır. Kırsal kesimde yaşayan kadından beklenen görev ve sorumluluklar farklıyken şehirde yaşayan kadından beklenen sorumluluklar ise farklılık göstermiştir( Vurgun, 2015: 4) Çarlık Döneminde ve Sovyetler Birliği Döneminde kadına yönelik tutumlar bu şekilde seyir gösterirken Kırgızistan da bu durumdan payına düşeni almıştır. Özellikle Çarlık Döneminde kızların onayı alınmadan aile onayı ile yapılan evlilikler, başlık parası, kaçırarak evlenme gibi durumlarla Kırgızistan'da da karşılaşılmıştır. 
Kırgızistan'daki bu durumun örneğini tarihte adını Datka ünvanı ile duyuran, ilk kez Datka ünvanı alan bir kadın olan Kurmancan Datka örneğinde görmekteyiz. Kurmancan Datka yani Manatbay kızı Kurmancanbübü, Oş şehrinin yakınındaki Orok kışlasında 1811 yılında dünyaya gelmiştir. Kurmancan yedi yaşındayken komşuları Törökul Bey’in oğlu Kulseyit ile kudalanır. Gelenek gereği de kıza küpe takılır. Kurmancan büyüyünce de evlendirilir. Kurmancan'ın evliliği bir yıl sürer, o sevmediği bir adamla yaşamaktan mutsuzdur, ata yurdunu özlemektedir. Kurmancan bir gece ata binip ata yurduna gelir. Eşi gelenekler gereğince arkasından adam gönderir ama adamlar Kurmancan'1 geri götüremezler. Bunun üzerine adamlara kalın parasının ${ }^{1}$ karşıllğınca at sürüsü verilir.( Bekturganova, 2006: 50). Kurmancan Datka o dönemlerde istenmeyen evlilik, başlık parası gibi durumları yaşayan pek çok kızdan sadece biridir. Ancak genel itibariyle kadına yönelik tutum bu şekildedir.

\section{Kırgız Atasözlerinde Kadın}

"Ayaldın çaçı uzun bolgonu menen akılı kıska", "Kadının saçı uzun aklı kısa." şeklindeki Kırgız atasözü toplum hayatı içerisinde kadına yönelik erkek egemen bakış açısını göstermektedir. Şavk (2002)'de yer alan Kırgız atasözlerinden hareketle, kadına toplum içerisinde verilen değer ve kadına biçilen rolleri anlamak mümkün olacaktır:

Acarduu ayal adamdın periştesi,

Akılduu ayal erkektin şerikteşi. (s.2)

"Güzel kadın, insanın meleği,

Akıllı kadın erkeğin ortağı."

At alsan minip al.

Ayal alsan süyüp al. ( s.29)

"At alırsan binip al,

Eş alacaksan sevip al.”

At mingendiki; ton, kiygendiki,

Ayal, tiygendiki; er, eldiki ( s.33).

"At, binenindir; elbise, giyenindir,

Kadın, evlenenindir; yiğit, halkındır."

Ayal cakşısın, eri süyöt,

Er cakşısın, eli süyöt( s. 40)

"Kadının iyisini kocası sever,

Yiğidin iyisini halk1 sever."

Cakşı ayal üydün caysanı,

Caman ayal üydün şaytanı( s. 82).

"Kötü kadın evin şeytanı

İyi kadın evin serdarı,"

Vazir cakşıl, kan cakşl,

Ayal cakşl, er cakşı ( s. 188).

"Vezir iyi, han iyi,

\footnotetext{
${ }^{1}$ Başlık parası.
} 


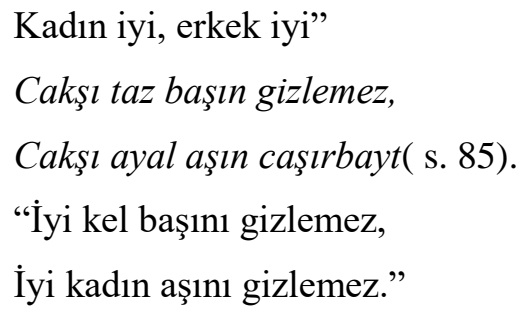

Atasözlerinde kadın deyince akla ev ve yemeğin geldiği, kadının eşine karşı görevleri ve yaşadığı toplum içerisinde bir duruşa sahip olması gerektiği anlaşılmaktadır. Kendisine pek çok rol ve görev biçilen Kırgız kadınının, geçmişten günümüze Kırgız sosyal ve toplumsal hayatı içerisinde genel itibariyle yaşadığ 1 toplum ve ailesi içerisinde bu görev ve rolleri yerine getirmesi beklenmiştir. Bugün Kırgızistan'da modern şekilde, büyük şehirlerde yaşayan kadınlardan bu özellikte görev ve sorumluluklar beklenmezken kırsal kesimde yaşayan Kırgız kadınından beklenen başlıca görevler şu şekildedir:

1. Boz üyün kurulması, sökülmesi ve taşıyıcıya yüklenmesi,

2. Hayvanlardan süt sağma, tereyağı ve peynir üretimi.

3. Deri işçiliği, ayakkabı, çorap, giyim eşyası imalatı gibi işlerle uğraşmak (Erdem, 2005: 237). Kırgız kültürü içerisinde kadından beklenen bu görev ve sorumlulukların oluşmasında hiç kuşkusuz ki yaşanılan coğrafyanın ve göçebe yaşam şeklinin büyük etkisi vardır. O halde Kırgız aile yaşantısı ve sosyal - kültürel hayatı içerisinde kadına biçilen rollerin oluşmasında yaşam şeklinin etkili olduğu açıktır. Göçebe bir yaşam şekline sahip Kırgızlarda, kadının rolü de buna göre şekillenmiştir. Bu açıdan bakıldığında Kırgız aile ve sosyal - kültürel hayatında Kırgız kadınını, aile hayatı içerisinde ve sosyal - kültürel hayat içerisinde değerlendirmek doğru olacaktır.

\section{Aile Hayatı İçerisinde Kırgız Kadını}

Kültürün devamlıllğında aile önemli bir yere sahiptir. Aile; topluma ait değerlerin, ritüellerin, uygulamaların ve inanışların devamını sağlayan bir kültür taşıyıcısıdır. Bu kültür taşıyıcıllğı rolünü de aile içerisinde daha çok anne ve baba üstlenmiştir. Özellikle bu görev aile içerisinde kadına yani anneye düşer. Geleneklerine bağlılığı ile dikkat çeken Kırgızlar da aile konusuna özel ilgi göstermişlerdir. Kırgızlarda aile bağı çok güçlüdür. Soy ve nesiller arası ilişkiler sağlam tutulur. Kırgızların İslam'ı kabulünden önce, ailenin korunması ve devamlılı̆̆ı, geleneksel dinî inanışlar ve töre sayesinde sağlanmış iken, onların Müslüman olmasından sonra dinî hükümlerin kontrolü, etkili olmuştur (Erdem, 2005: 246). Aile hayatı içerisinde kadın; eş olarak, anne olarak, gelin olarak, aile büyüğü olarak, evlat olarak düşünüldüğünde kadının aile içerisinde farklı rollere sahip olduğu görülür. Kırgız kadınına da bu açıdan bakıldığında aile içerisinde Kırgız kadını pek çok role sahiptir:

\section{Eş Olarak Kırgız Kadını}

Kırgız kadınının aile içerisindeki önemli rollerinden biri eş olmaktır. Kırgız kadını günümüzde sevdiği kişiler ile hayatlarını kurarlarken, geçmişte Kırgız toplumsal hayatında evliliğin bu şekilde gerçekleşmediği çeşitli uygulamalardan anlaşılmaktadır. Ailenin özellikle babanın uygun gördüğü kiși ile kız evlendirilmektedir. Eş olarak kadın; ailenin, babanın onayıyla seçilmektedir. Evlilikle ilgili bazı uygulamalarda kadının aile içerisindeki yerini görmek mümkün olacaktır. Bel kudalık, başlık parası, kız kaçırma gibi uygulamalarda kadına yönelik tutum ve alg1 tespit edilebilir:

\section{Bel Kudalık}

Kırgızlarda çocuk doğmadan söz kesilir, dünür olunur. Buna Kırgızlar "bel kudalık" derler (Dıykanbayeva, 2013: 132). Bel kuda, Kırgız kültüründeki evlenme çeşitlerinden biridir. Henüz doğmamış veya birisi doğmuş, diğeri anne karnında olan çocukların birbirleriyle 
sözlendirilmesi durumudur. Bu uygulama ile henüz doğmamış kız çocuğu eş olarak seçilmiş olur.

\section{Başlık Parası}

Kırgızlarda nişan gerçekleşmeden önce mutlaka başlık parasını belirlemek gerekir. Erkek tarafı kız tarafına dünür olmak için gittiğinde bu durum görüşülür. Başlık, para olabileceği gibi hayvan da olabilir. Kırgızlar başlık parasına "kalın" derler. Eskiden kalın sadece kızın ailesi veya babasına değil, kızın ait olduğu tüm aşirete ödenirken daha sonraları sadece yakın akrabalara, sonunda da sadece kızın babasına ödenmeye başlanmıştır (Yüce ve Dosbayeva, 2007). Eskiden kalın kızın sülalesine ödenirken günümüzde sadece babaya ödenmektedir ( Dıykanbayeva, 2013: 136).Başlık parası uygulaması da eş olarak kadına toplumsal açıdan bakış açısını göstermesi bakımından önemlidir.

\section{Kız Kaçırma}

Kız kaçırma eski bir evlenme şeklidir. Kız kaçırma iki şekilde gerçekleşebilir. Hem kızın hem de kızın ailesinin evliliğe rızası yoksa ya da kızın rızası olup ailenin rızası yoksa gençler anlaşıp kaçarlar. Bazen de başlık parasını çok bulan genç, başlık parasını ödememek için sevdiği kızı kaçırır( Ayunakulova, 2006: 102). Bu evlilik çeşidi ile eş olarak seçilen kız, bazen rızası ile bazen de rızası dışında eş olarak seçilmiş olur.

Tüm evlilik şekillerinde erkek egemen anlayışın hâkim olduğu görülür.

\section{Anne Olarak Kırgız Kadını}

Türk toplumlarında kabul edilmiş bir gerçek vardır ki o da çocuk bakmanın kadının rolü olduğu fikridir. Kadın, anne rolüyle çocuğunun ilk olarak yaşamsal ihtiyaçlarını karşılamakla görevlidir. Annelik çocuk daha doğmadan kadının hamileliği ile başlayan bir süreçtir. Anne adayı kadın; bebeğinin gelişimi için daha iyi beslenmeye, yaşam şekline dikkat etmeye, bebeğine zarar verebilecek kötü alışkanlıklarından (sigara, alkol vb. ) uzak durmaya başlar. Kadın, toplum içerisinde kendisine biçilen annelik rolüne bu şekilde hazırlanır. Çocuğun dünyaya gelmesiyle çocuğun temel yaşamsal ihtiyaçları anne tarafından giderildiği gibi, çocuk büyüdükçe çocuğun psikolojik ve duygusal ihtiyaçları da giderilmelidir. Anne ve çocuk ilişkisine yönelik olarak yapılan pek çok araştırma şunu gösterir ki sevgi, disiplin ve özgürlük çocuğun temel ruhsal gereksinimlerinin karşılanması anlamına gelmektedir (Sürücü, 2005:171).

Türk toplumlarında kabul görmüş olan çocuğa annenin baktığı yönündeki fikir Kırgızlarda da geçerlidir. Kırgızlara göre anne, çocuğun şekillenmesinde önemli bir kişiliktir. Özellikle Kırgız atasözlerinde geçen "Ene toodogu bulak, bala çöldögü kulan.”, "Anne dağdaki kaynak, çocuk çöldeki kulun." "Eneden süt iç, akılmandan akıl iç." ,"Anneden süt iç, bilgin adamdan akıl iç.",Enelüü balanın özü tok, enesiz balanın közü tok." "Anneli çocuğun kendi tok, annesiz çocuğun gözü toktur.”, “ Enenin kolunan klz toyboyt, erdin kolunan kuş toyboyt." "Anne elinden kız doymaz, er elinden kuş doymaz." (Güngör ve Cailova Güngör, 1998: 188) şeklindeki atasözleri aslında toplum içerisinde anne olarak kadına düşen rolü ve anneye yönelik anlayışı gözler önüne sermektedir. Söz konusu atasözlerine göre anne, olarak kadın çocuğu için bir kaynaktır yani çocuk her açıdan annesinden faydalanır. Anne olarak kadın, önce onu dokuz ay karnında taşıyan, sonra da çocuğuna sütünü veren, onun karnını doyuran bir kişidir.

\section{Gelin Olarak Kırgız Kadını}

Kırgız kültüründe gelinle ilgili bazı toplumsal beklentiler ve değer yargıları vardır. Bunlardan bazıları şöyledir:

1. Gelinin çeyizi olmalıdır. Kırgız kültüründe çeyizsiz gelin değersiz olarak nitelendirilir. Nasıl ki kalının miktarı güveyin değerini belirliyorsa çeyizin olup olmaması da gelinin değerini belirlemektedir( Diykanbayeva, 2013: 137). 
2. Gelin kıyafetleriyle de artık evli kadın gibi olmalıdır. Evli kadın gibi saçları örülmeli, evli kadınların giydiği "eleçek" adı verilen başlığı kullanmalıdır.

3. Gelinin çocuğu olmalıdır. Yoksa toplumun gözünde gelin değersiz, uğursuz görülür.

Kırgız atasözleri içerisinde gelinle ilgili değer yargılarını görmek mümkündür. Atasözleri içesinde gelin hakkındaki düşünceler şu şekildedir:

Keleer ( Kelgen) sözdü kelin da aytat.

“Gelecek ( gelmiş) sözü gelin bile söyler.” ( Şavk, 2002: 142)

Kelindi kelgende kör,

Kempirdi ölgöndö kör.

"Gelini geldiğinde gör,

Kocakarıyı öldügünde gör.” ( Şavk, 2002: 142).

Kelindin betin kim açsa, oşol ısık.

“Gelinin yüzünü kim açarsa, o, sıcak ( cana yakın görünür)” ( Şavk, 2002: 143).

Keçinde kün klzarsa, kelinin erkek törögöndöy süyün.

Erten menen kün kizarsa,

Eline coo tiygendey küyün.

"Akşamleyin güneş kızarsa,

Gelinin erkek doğurmuş gibi sevin.

Sabahleyin güneş kızarsa,

Ülkeni düşman basmış gibi üzül” ( Şavk, 2002: 141).

\section{Aile Büyüğü Olarak Kırgız Kadını (Kayınene, Baybiçe)}

Aile bireyleri arasındaki ilişkilere bakıldığında aile bireyleri arasında bir hiyerarşinin olduğu açıktır. Ataerkil toplumlarda baba ailenin reisidir, ailede ilk söz söyleme hakkı ona aittir. Babadan sonra kadınlar arasında söz sahibi olan bir başka aile bireyi ise kaynanadır. İçinde yaşadığ 1 toplumun ve kültürün etkisiyle üzerine biçilen büyük rollerden biri de evin büyüklerinden biri olan kaynanaya aittir. Otorite sağlama anlayışıyla aile içi hiyerarşik düzende kayınvalidenin düzeni ve işleyişi sağlama noktasında söz söyleme hakkına sahip olduğu görülür. Türk atasözleri arasında geçen "Oğlan anası kapı arkası, kız anası minder arkası.", "Klzım sana söylüyorum, gelinim sen anla." ( Ersöz, 2010: 177). Bu anlayış1 göstermektedir. Kırgız kültüründe de "Keregem saga aytam, kelinim sen uk." "Keregem sana söylüyorum, gelinim sen dinle.", şeklinde geçen atasözleri Türk ve Kırgız kültürü içerisinde gelin-kaynana ilişkilerinin bir örneği şeklinde düşünülebilir.

Kaynanadan sonra aile büyüğü olarak Kırgızlarda aile içerisindeki rolüyle "baybiçe" dikkat çekmektedir. Çok eşli evliliğin bazı durumlarda gerçekleşmesi nedeniyle Kırgızlarda ilk nikâhlı eşe "baybiçe" denilir. Türkiye Türkçesinde bu kelimenin tam karşıllğı yoktur; onun yerine "büyük hanım, ilk eş" gibi tanımlar kullanılabilir. Baybiçe, eski dönemlerde Kırgızlarda çok eşli erkeklerin ilk eşlerine verilen isimdir ( Karataev ve Eraliev:2005, 55). Toplumsal hayatta baybiçeler saygı duyulan, akıl danışılan ve pek çok toplumsal uygulamada önemli görevleri olan, kız isteyen, göbek bağı kesen önemli kişilerdir. İnsanlar onların tecrübelerinden yararlanır. Kendi evinde gördüğü saygıyı baybiçe, toplumsal hayatta da görür. 


\section{Evlat Olarak Kırgız Kadını}

Kırgız kültürü içerisinde bir kural haline gelen "Kıza kırk evden yasak gerek.” sözü toplum içerisinde kız evlada bakışı ve anlayışı göstermektedir. Kırgızlara göre kız çocuğu baba evinde misafirdir, baba evinde geçicidir. Kız büyüyünce baba evinden gider, evini bırakır. Kız çocuğunun toplum hayatında üzerlerine biçilen rolleri ve bu rollere göre şekillenen hareketleri ve davranış biçimleri vardır. Toplumsal rollerine göre kızlar büyüdüklerinde evlenmeli, yemek yapmayı öğrenmelidir ve anne olmalıdırlar.

\section{Sosyal ve Kültürel Hayat İçerisinde Kırgız Kadını}

\section{Süs ve Giyimiyle Kırgız Kadını}

Bugün modern hayatlar içerisinde değişen anlayışla birlikte Kırgız kadını modern kıyafetler içerisinde görülürken özellikle geçmiş dönemlerde ve kırsal yaşamda, Kırgız halkının sosyal ve toplumsal hayatı içerisinde kullandıkları kıyafetlerin, özellikle de kadın kıyafetlerinin sosyolojik bir gösterge olduğu görülür. Örneğin giydiği kıyafetiyle, taktığı başlığıyla ya da saçındaki süsü ve örgüsü ile Kırgız kadının evli olup olmadığı anlaşılmaktadır. Evli bir kadın olarak Kırgız kadınının iki örgülü saçları vardır ve eleçek adı verilen başlığı giyer. Bir diğer evli kadın kıyafeti ise beldemçedir. ${ }^{2}$ Beldemçe sadece evli kadınlar tarafından kullanılır. Onu bekâr kızlarda görmek mümkün değildir. Ayrıca yeni geline beyaz başörtüsü örtülür, beyaz gömlek giydirilir.

\section{Ritüelleri Gerçekleștiren Kırgız Kadını}

Pek çok uygulamada ve ritüelde kadının rol aldığı ve pek çok uygulamayı ve ritüeli kadının gerçekleştirdiği görülür. Doğumla, evlilikle ve ölümle ilgili pek çok ritüelde ve uygulamada kadınlar önemli rollerde yer alır. Doğumla ilgili ritüellerde kadın önemlidir. Kadın çocuk daha doğmadan üzerine sorumluluk alır ve çocuk için hazırlık yapmaya başlar. Çocuğun göbeğinin kesimi, kırk çıkarma, beşik toyu gibi pek çok ritüeli kadın gerçekleştirir.

Evlikle ilgili uygulamalarda bir kadın olarak yenge çok önemlidir. Anne ve babadan sonra evlilikle ilgili yapılan geleneklerde yenge başrolde yer alır. Kızın istenmesinden başlayarak, evden çıkışına kadar pek çok uygulamada yenge önemli görevlerde yer almaktadır. Yengenin özellikle gelin için bu kadar önemli gözükmesi, kendisinin de daha önce gelin olması ve aynı şeyleri yaşamasından kaynaklanmaktadır. Yenge, kız ve oğlan için anne ile babaları arasındaki sözcüleri ya da yardımcılarıdır. Hatta Kırgız kültürü içerisinde cenketay "yenge toyu" olarak adlandırılan bir toy bile bulunmaktadır. ${ }^{3}$

\section{Çocuk Sahibi Olan / Çocuk Sahibi Olmayan Kırgız Kadını}

Kırgızlarda da çocuk ve çocuk sahibi olmak çok önemlidir. $\mathrm{Bu}$ önemi Manas Destanı'ndan da anlamak mümkündür. Manas Destanı'nda Manas'ın babası Cakıp Han on dört yıllık eşi Çıırçı'dan bir erkek çocuğa sahip olmadığı için üzgündür. Çeşitli ritüellerden sonra ilerlemiş yaşlarına rağmen çocuk sahibi olurlar (Yıldız, 2009: 79) . Kırgız kültüründe çocuğu olmayan kadınlar toplum içerisinde bahtsız olarak nitelendirilirler ve çocuk sahibi olabilmeleri için de farklı uygulamaları yerine getirirler. (Sağlık merkezlerine gitme, halk hekimlerine gitme, mezar gezme, kurban kesme, halkın duasını alma...) Çocuksuzluğun bahtsız bir durum olduğunu atasözleri de gösterir: "Bee tuumayınça baytal atı kalbayt, katın tuumayınça kelin atı kalbayt.", "Kısrak doğurmayınca baytal adı kalmaz, kadın doğurmayınca da gelin adı kalmaz." "Tuubagan katından ulaktuu eçki artık." "Doğum yapmamış kadından oğlaklı keçi daha iyidir." diye söylenir (Usubaliyeva, 2013). Çocuksuzluk, toplumun gözünde kadına değersizlik verir. Bu durumun tam tersi olarak çocuk sahibi olan kadın ise toplumun gözünde değer kazanır.

\footnotetext{
${ }^{2}$ Kadife, çuha gibi kumaşlardan yapılan iç kısmına pamuk, yün, bazen ince keçe bazen de koyun-keçi derilerinin dikildiği, kemere çok benzeyen sonbaharda, baharda ve kışın kullanılan geleneksel kadın giysilerinden biridir.

${ }^{3}$ Yenge, damat kızın evine gelince ondan bir toy ister. Bu toya verilen isimdir.
} 


\section{Sonuç}

Sonuç olarak Kırgız kültüründe kadına aile ve toplum hayatı içerisinde çeşitli roller verilmiştir. Aile hayatı ve sosyal - kültürel hayat içerisinde kadına biçilen bu rollerin şekillenmesinde göçebe Kırgız yaşamının etkili olduğu ve kadının dünyasının bu yaşam şekliyle bağlantılı olarak şekillendiği görülür. Bu roller içerisinde kadın geleneksel anlayış içerisinde yer almış, toplumsal cinsiyet rollerinin çizdiği sınırlar içerisinde üzerine düşen rolleri yerine getirmiştir. Kadın; eş olarak kocasına, evlat olarak anne ve babasına, anne olarak da çocuklarına karşı çeşitli rollere sahip olmuştur. Kısacası kadınlar geleneğin devamında, aile ve toplumsal hayatın şekillenmesinde önemli görevleri ve rolleri üstlenmişlerdir. Kimi zaman ritüelleri yerine getirirken kimi zaman da çocuğunun toplumsal kimliğini kazanmasında ve toplumsal rolünü benimsemesinde şekillendirici rol üstlenmiştir. Kırgız kültüründe de kadın; anne, eş, büyük olarak üzerine düşen toplumsal cinsiyet rollerini yerine getirmiştir.

\section{Kaynakça}

AYNAKULOVA, G., ( 2006). Kırgızlarda Evlilik ve Evlenme Törenleri. Milli Folklor. Say1 72, s. 95-106.

BEKTURGANOVA, K., ( 2006). Kırgızistandın Asıl Kızdarı. Birinçi Kitep. Bişkek: Mamlekettik Til Cana Entsiklopediya Borboru.

COŞAR, H., ( 2013). Tarihte ve Günümüzde Kadın. Ankara: Kardelen Ofset.

DIYKANBAYEVA, M., ( 2013). Kırgız Türklerinde Evlilik ve Buna Bağlı İnanışlar. A. Ü. Türkiyat Araştırmaları Dergisi ( TAED). s. 131-144.

ERDEM, M. (2005)., Klrgız Türkleri Dinî ve Sosyal Hayat. Ankara: Türkiye Diyanet Vakfı Yayın Matbaacılık ve Ticaret İşletmesi.

ERSÖZ, A. G., (2010). Türk Atasözleri ve Deyimlerinde Kadına Yönelik Toplumsal Cinsiyet Rolleri. Gazi Türkiyat, Say1 6, s. 167-181.

GÜNGÖR, A., GÜNGÖR A. C., (1998) Kırgız Atasözleri. Ankara: Kültür Matbaası.

HASDEMIR, T. A., (1991). Sovyetler Birliği'nde Kadının Durumu. Amme İdaresi Dergisi, C. 24, S. 3, s. 81-98. Basımevi.

İNAN, A. (1998)., Makaleler ve Incelemeler I. Cilt. Ankara: Türk Tarih Kurumu Bişkek.

KARATAEV, O. K., ERALiYEV, S. N. (2005). Kırgız Etnografiyası Boyunca Sözdük.

SÜRÜCÜ, A., (2005). Anne-Baba Çocuk İletişimi. Öğretmenin Dünyası, Sayı 169.

ŞAVK, Ü. Ç., ( 2002). Kırgız Atasözleri. Ankara: Atatürk Kültür, Dil ve Tarih Yüksek Kurumu Türk Dil Kurumu Yayınları.

ŞEN, S., ( 2003). Oğuz Kağan Destanı'nda ve Dede Korkut Hikâyelerinde Kadın. A. Ü. Üniversitesi Türkiyat Araştırmaları Enstitüsü Dergisi, Sayı 21, s. 123-128. 

İşenimder.

USUBALİEVA, A., ( 2013) Balanın Törölüşünö Çeyinki Irım-Cırımdar Cana

VURGUN, S. Y. ( 2015). XVII. Yüzyılın İlk Yarısından XX. Yüzyılın İlk Yarısına Kadar Türkistan'da Kadın. Türk Dünyası Araştırmaları, Sayı 214, s. 1-14.

YILDIZ, N., (2009). Türk Destanc1lık Geleneği. Modern Türklük Araştırmaları Dergisi, Say1 6, s. 7-15.

YÜCE, M., DOSBAYEVA B., (2007). Kırgız Türklerinde Evlenme Geleneği. Modern Türklük Araştırmaları Dergisi, Cilt 4, Sayı 1, s. 7-24. 